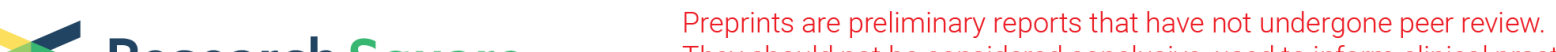 Research Square They should not be considered conclusive, used to inform clinical practice, or referenced by the media as validated information.
}

\section{The Reconstruction Accuracy of the Hip Center of Rotation After Cementless Total Hip Arthroplasty for Failed Treatment of Acetabular Fractures. Does It Matter?}

\section{Liang Zhang}

Department of Orthopaedic, Beijing Jishuitan Hospital, Fourth Clinical College of Peking University Mingxue Chen

Department of Orthopaedic, Beijing Jishuitan Hospital, Fourth Clinical College of Peking University

\section{Zhuyi Ma}

Department of Orthopaedic, Beijing Jishuitan Hospital, Fourth Clinical College of Peking University

\section{Tao Bian}

Department of Orthopaedic, Beijing Jishuitan Hospital, Fourth Clinical College of Peking University

\section{Shaoliang Li}

Department of Orthopaedic Trauma, Beijing Jishuitan Hospital, Fourth Clinical College of Peking University

\section{Weiyi Li}

Department of Physical Therapy and Rehabilitation, Beijing Jishuitan Hospital, Fourth Clin-ical College of

Peking University

Yixin Zhou ( $\square$ orthoyixin@yahoo.com)

Department of Orthopaedic, Beijing Jishuitan Hospital, Fourth Clinical College of Peking University

\section{Research Article}

Keywords: Arthroplasty, acetabular fracture, center of rotation, cementless

Posted Date: November 18th, 2021

DOI: https://doi.org/10.21203/rs.3.rs-1057572/v1

License: (1) This work is licensed under a Creative Commons Attribution 4.0 International License. Read Full License 


\section{Abstract \\ Background}

To assess the impaction of reconstruction accuracy of hip center of rotation (COR) on midterm clinical and radiographic results of cementless reconstruction of total hip arthroplasties (THAs) for patients after failed treatment of acetabular fractures.

\section{Methods}

One hundred and four patients (107 hips) who underwent THAs after failed treatment of acetabular fractures were retrospectively evaluated and cementless cups and stems were implanted in all hips. Clinical outcomes were assessed using the Harris hip score (HHS) and Western Ontario and McMaster Universities Arthritis Index (WOMAC) scoring system. Radiographic results were analyzed by serial perioperative $\mathrm{x}$-rays.

\section{Results}

At the latest follow-up examination, the median HHS increased from 52 (42-65) before surgery to 93 (90-97) (p $<0.001)$ and the median WOMAC decreased from $52(36-65)$ before surgery to $5.8(1.5-8)(p<0.001)$. Compared with normal contralateral hip, 79 cups migrated superiorly $(0.2-33.6 \mathrm{~mm})$ and 22 cups migrated inferiorly $(0.2-16.1 \mathrm{~mm})$. The distance of superior migration of reconstructed COR was correlated with positive Trendelenburg sign at the latest follow-up examination $(r=0.504 ; p<0.001)$. The percentage of postoperative Trendelenburg sign was significantly higher in superior migration subgroup than that in subgroup with anatomical restoration of $\operatorname{COR}(P=0.015)$.

\section{Conclusions}

Cementless THAs in patients after failed treatment for acetabular fractures achieved predictable clinical and radiographic outcomes. A superiorly migrated hip COR appeared to exert a negative effect on abductor muscle function.

\section{Background}

Optimal restoration of hip center of rotation (COR) is of great importance for implant longevity in total hip arthroplasty (THA). Any errors in reconstruction of hip COR can inevitably affect implant load, stability, wear rates and can eventually result in poor hip function with costly complications, including pain, loosening and dislocation $[1,2,3,4,5]$.

Acetabular fractures may lead to late complications, including posttraumatic arthritis and avascular necrosis of femoral head with or without initial open reduction and internal fixation (ORIF) [6, 7]. THA has been utilized to treat patients with disabling pain and functional limitations after failed treatment of acetabular fractures. Previous literature has demonstrated encouraging outcomes with regard to cementless acetabular 
components $[8,9,10,11,12,13]$. Among these, previous articles ever described the reconstructive accuracy of hip COR after THA, but failed to compare it with clinical results $[8,9,10]$.

The purpose of this study was to retrospectively review a single center's experiences in treating failed acetabular fractures with THA by cementless components. An additional purpose was to assess whether the reconstructed hip COR affects clinical results and complication rate.

\section{Methods}

Between 2001 and 2017, 124 consecutive patients were treated at our institute with primary THAs after failed treatment of acetabular fractures. The median duration of follow-up was 93.0 months (47-151 months) in 104 patients (107 hips) (Table 1); 20 patients were lost to monitoring. Approval of the local institutional review board and informed consent from all participating patients were obtained.

Table 1

Comparison of Preoperative Demographic and Clinical Study Data

\begin{tabular}{|c|c|c|c|}
\hline Variable & Data Group 1 & Data Group 2 & Total \\
\hline Gender & 78 men $(75 \%)$ & 26 women $(25 \%)$ & 104 patients \\
\hline Cause of fracture & $\begin{array}{l}\text { Motor vehicle } \\
\text { accident in } 83 \text { hips } \\
(77.6 \%)\end{array}$ & $\begin{array}{l}\text { Weight-compression injuries in } 5 \text { hips } \\
(4.6 \%) \text {; fall from a height in } 19 \text { hips } \\
(17.8 \%)\end{array}$ & $\begin{array}{l}107 \text { hips in } \\
\text { high-energy } \\
\text { accidents }\end{array}$ \\
\hline Treatment & $\begin{array}{l}\text { ORIF in } 67 \text { hips } \\
(63 \%)\end{array}$ & $\begin{array}{l}\text { Conservative treatment in } 40 \text { hips } \\
(37 \%)\end{array}$ & \\
\hline BMI & $25.8 \pm 3.7$ & & \\
\hline $\begin{array}{l}\text { Average age at fracture } \\
(\mathrm{yr})\end{array}$ & 40 (range, 33-48.5) & & \\
\hline $\begin{array}{l}\text { Average age at THA } \\
\text { (yr) }\end{array}$ & 50 (range, 43-47) & & \\
\hline $\begin{array}{l}\text { Treatment interval } \\
\text { between fracture and } \\
\text { THA (mo) }\end{array}$ & 47 (range, 18-156) & & \\
\hline Positive Thomas sign & 68 hips (63.6\%) & & \\
\hline $\begin{array}{l}\text { Positive Trendelenburg } \\
\text { sign }\end{array}$ & 57 hips (53.3\%) & & \\
\hline
\end{tabular}

ORIF = open reduction and internal fixation; BMI=body mass index; THA= total hip arthroplasty.

The initial fracture pattern was classified according to Judet classification system (Table 2). We exposed all 107 hips through a posterolateral approach. Hardware was partially removed in 21 hips, entirely in 26 hips, and left in situ in 20 hips. We implanted tantalum trabecular metal (TM) (Zimmer, Warsaw) cups in 38 hips and titanium hemispheric cups in the other 69 hips. In 69 cases, the cups were supplemented with 2 to 5 screws and the initial stability and orientation of the cup was confirmed with intraoperative radiographs. Cementless stems were implanted in all hips. We used a ceramic-on-ceramic bearing surface in 38 hips (35.5\%), a ceramic- 
on-polyethylene bearing surface in 45 hips (42.1\%), and a cobalt-chrome head on a polyethylene bearing surface in 24 hips (22.4\%).

Table 2

Initial fracture pattern according to Judet system ${ }^{17}$

\begin{tabular}{|l|l|}
\hline Fracture pattern & $\mathbf{N}(\%)$ \\
\hline Simple fractures & $69(64.5 \%)$ \\
\hline Posterior wall & $59(55.1 \%)$ \\
\hline Posterior column & $3(2.8 \%)$ \\
\hline Transverse & $7(6.5 \%)$ \\
\hline Complex fractures & $38(35.5 \%)$ \\
\hline Posterior column plus posterior wall & $20(18.7 \%)$ \\
\hline Both columns & $4(3.7 \%)$ \\
\hline Transverse plus posterior wall & $12(11.2 \%)$ \\
\hline $\begin{array}{l}\text { T-shaped } \\
\text { Acetabular bone defects were classified according to the Paprosky criteria [14]. There were 22 grade I } \\
\text { acetabular defects, 17 grade lla defects, 15 grade llb defects, 7 grade llc defects, } 3 \text { grade Illa defects and } 1 \\
\text { grade Illb defects. Thirty-six hips had acetabular bone autografts: 27 had morcelized autografts and } 9 \\
\text { received bulk autografts. }\end{array}$ \\
\hline
\end{tabular}

\section{Methods}

Between 2001 and 2017, 124 consecutive patients were treated at our institute with primary THAs after failed treatment of acetabular fractures. The median duration of follow-up was 93.0 months (47-151 months) in 104 patients (107 hips) (Table 1); 20 patients were lost to monitoring. Approval of the local institutional review board and informed consent from all participating patients were obtained. 
Table 1

Comparison of Preoperative Demographic and Clinical Study Data

\begin{tabular}{|c|c|c|c|}
\hline Variable & Data Group 1 & Data Group 2 & Total \\
\hline Gender & 78 men $(75 \%)$ & 26 women $(25 \%)$ & 104 patients \\
\hline Cause of fracture & $\begin{array}{l}\text { Motor vehicle } \\
\text { accident in } 83 \text { hips } \\
(77.6 \%)\end{array}$ & $\begin{array}{l}\text { Weight-compression injuries in } 5 \text { hips } \\
(4.6 \%) \text {; fall from a height in } 19 \text { hips } \\
(17.8 \%)\end{array}$ & $\begin{array}{l}107 \text { hips in } \\
\text { high-energy } \\
\text { accidents }\end{array}$ \\
\hline Treatment & $\begin{array}{l}\text { ORIF in } 67 \text { hips } \\
(63 \%)\end{array}$ & $\begin{array}{l}\text { Conservative treatment in } 40 \text { hips } \\
(37 \%)\end{array}$ & \\
\hline BMI & $25.8 \pm 3.7$ & & \\
\hline $\begin{array}{l}\text { Average age at fracture } \\
\text { (yr) }\end{array}$ & 40 (range, 33-48.5) & & \\
\hline $\begin{array}{l}\text { Average age at THA } \\
\text { (yr) }\end{array}$ & 50 (range, 43-47) & & \\
\hline $\begin{array}{l}\text { Treatment interval } \\
\text { between fracture and } \\
\text { THA (mo) }\end{array}$ & 47 (range, 18-156) & & \\
\hline Positive Thomas sign & 68 hips (63.6\%) & & \\
\hline $\begin{array}{l}\text { Positive Trendelenburg } \\
\text { sign }\end{array}$ & 57 hips (53.3\%) & & \\
\hline
\end{tabular}

ORIF = open reduction and internal fixation; BMI=body mass index; THA= total hip arthroplasty.

The initial fracture pattern was classified according to Judet classification system (Table 2). We exposed all 107 hips through a posterolateral approach. Hardware was partially removed in 21 hips, entirely in 26 hips, and left in situ in 20 hips. We implanted tantalum trabecular metal (TM) (Zimmer, Warsaw) cups in 38 hips and titanium hemispheric cups in the other 69 hips. In 69 cases, the cups were supplemented with 2 to 5 screws and the initial stability and orientation of the cup was confirmed with intraoperative radiographs. Cementless stems were implanted in all hips. We used a ceramic-on-ceramic bearing surface in 38 hips (35.5\%), a ceramicon-polyethylene bearing surface in 45 hips (42.1\%), and a cobalt-chrome head on a polyethylene bearing surface in 24 hips (22.4\%). 
Table 2

\begin{tabular}{|c|c|}
\hline Fracture pattern & $\mathbf{N}(\%)$ \\
\hline Simple fractures & $69(64.5 \%)$ \\
\hline Posterior wall & $59(55.1 \%)$ \\
\hline Posterior column & $3(2.8 \%)$ \\
\hline Transverse & $7(6.5 \%)$ \\
\hline Complex fractures & $38(35.5 \%)$ \\
\hline Posterior column plus posterior wall & $20(18.7 \%)$ \\
\hline Both columns & $4(3.7 \%)$ \\
\hline Transverse plus posterior wall & $12(11.2 \%)$ \\
\hline T-shaped & $2(1.9 \%)$ \\
\hline
\end{tabular}

Acetabular bone defects were classified according to the Paprosky criteria [14]. There were 22 grade I acetabular defects, 17 grade lla defects, 15 grade Ilb defects, 7 grade Ilc defects, 3 grade Illa defects and 1 grade IIlb defects. Thirty-six hips had acetabular bone autografts: 27 had morcelized autografts and 9 received bulk autografts.

\section{Clinical And Radiographic Evaluation}

All clinical evaluations were conducted by independent observers (C.M.X., L.W.Y.) who had not participated in the THAs. All patients were routinely examined at three months, six months, one year, yearly until 5 years after surgery and then every 5 years thereafter. For patients who did not comply with routine follow-up schedules, data collection was accomplished via telephone, E-mail, or WeChat software. Clinical outcomes were evaluated using the Harris hip score (HHS) and Western Ontario and McMaster Universities (WOMAC)Arthritis Index scoring system. Patient satisfaction was also evaluated using a self-administered four-category scale (very satisfied, somewhat satisfied, somewhat dissatisfied, and very dissatisfied).

Serial radiographs included anteroposterior (AP), lateral, and two $45^{\circ}$ oblique views of the involved hip before THA and at the follow-up visit. Computed tomography scans of the involved pelvis were routinely reviewed preoperatively. Radiographic assessments of acetabular components were accomplished in three zones, as devised by DeLee and Charnley [15]. Radiographic failure was determined by $>3 \mathrm{~mm}$ of vertical or horizontal migration, $>5^{\circ}$ change in inclination angle and presence of fewer than two signs of osteo-integration according to Moore criteria [16]. Heterotopic ossification ( $\mathrm{HO}$ ) was categorized by the classification system of Brooker et al [17]. The acetabular inclination and anteversion angles were measured according to the method described by Widmer [18]. $40 \pm 10^{\circ}$ for inclination and $15 \pm 10^{\circ}$ for anteversion were regarded as the safe zone proposed by 
Lewinnek et al [19]. Preoperative, postoperative, and the change in leg length discrepancy (LLD) were recorded. The LLD is measured from the inter-teardrop line to the midpoint of the lesser trochanter on both sides.

The vertical and horizontal locations of cups were documented according to the method described by Martel et al [20]. Patients who had undergone bilateral THA or who had abnormal contralateral hips were excluded. We calculated the difference between each horizontal and vertical distance in the reconstructed hip and in the contralateral hip. All radiographs reviewed were at the latest follow-up examination from the electronic picture archiving and communication system (PACS) in our institute and the magnification ratio was determined from the known diameter of implanted prosthetic head. Each parameter was measured twice with Mimics software (version 16.0) and averaged.

The statistical analysis was used by SPSS software (version 17.0). Descriptive analyses for categorical variables were based on percentages and frequencies and for continuous variables on mean and standard deviation (SD) or median and quartile (25-75\%) if the data were skewed. The preoperative and final follow-up HHS and WOMAC were compared using the Wilcoxon signed rank test. The correlations between continuous variables and ordinal variables were determined using Pearson correlation analysis and Spearman rank correlation analysis by correlation coefficient $(r)$, respectively.

The method for intergroup comparisons were as follows. 101 hips with unilateral hip replacement were classified into an inferior migration subgroup (inferior migration distance of the reconstructed COR $>5 \mathrm{~mm}$ ), superior migration subgroup (superior migration distance $>5 \mathrm{~mm}$ ) and subgroup with anatomical restoration (inferosuperior migration distance equal or less than $5 \mathrm{~mm}$ ). Similarly, these hips were classified into a medial migration subgroup (medial migration distance $>5 \mathrm{~mm}$ ), lateral migration subgroup (lateral migration distance $>5 \mathrm{~mm}$ ) and subgroup with anatomical restoration (mediolateral migration distance equal or less than $5 \mathrm{~mm}$ ). For the cases with superior migration of reconstructed COR, hips were classified into a subgroup with anatomical restoration (0-5mm), a subgroup with mild migration $(5-10 \mathrm{~mm})$, a subgroup with moderate migration (10-20 mm) and a subgroup with severe migration ( $\geq 10-20 \mathrm{~mm}$ ). The statistical analysis was used to examine the differences between the variables describing these subgroups, including patient demographics (gender, age at THA, BMI, treatment interval, preoperative HHS and WOMAC), trauma-related factors (fracture pattern, initial ORIF treatment, preoperative LLD) and surgery-related factors (acetabular inclination and anteversion angle, use of an elevated liner, cup diameter, and bulk autografts). We also analyzed the differences between these subgroups regarding postoperative outcomes including LLD, Trendelenburg sign, HHS and WOMAC, and complication rate. The intergroup differences were compared by using Kruskal-Wallis tests or Fisher exact tests for continuous variables and for dichotomous variables, respectively. Significance was set at $p<0.05$, and tests were 2 -tailed.

\section{Results}

\section{Clinical assessment}

The average HHS increased from 52 (42-65, range, 20-81) before surgery to 93 (90-97, range 59-100) at the latest follow-up examination ( $p<0.001$ ). There were excellent results in 83 hips, good for 15, fair for 2 and poor for an additional 7. The average WOMAC decreased from 52(36-65, range, 8-93) before surgery to 5.8 (1.5-8, range, $0-36)$ at the latest follow-up examination $(p<0.001)$. 
After THA, the Thomas and Trendelenburg signs were positive in 8 (7.5\%) and 18 hips (16.8\%), respectively. All but seven patients were very satisfied (75 patients) or satisfied ( 22 patients) with the results. Four patients who were very dissatisfied all developed periprosthetic infection. Three patients were somewhat dissatisfied. One of them had an iatrogenic sciatic nerve injury, one patient had perceived LLD and another one endorsed persistent thigh pain.

\section{Radiographic results}

The overall inclination and anteversion angles of cups were $38.0 \pm 7.5^{\circ}$ (range, $13.5-58.3^{\circ}$ ) and $17.8 \pm 7.1^{\circ}$ (range, 3.0-34. $\left.7^{\circ}\right)$, respectively. Of the 107 hips, 20 (18.7\%) were outside of Lewinnek acetabular anteversion safe zone (16 hips $>25^{\circ}$ and 4 hips $<5^{\circ}$ ) and $17\left(15.9 \%\right.$ ) were outside inclination safe zone ( 5 hips $>50^{\circ}$ and 12 hips $<30^{\circ}$ ). Only 3 hips had an inclination angle of $<30^{\circ}$ and an anteversion angle of $<5^{\circ}$ simultaneously.

The mean $x$-ray measured LLD decreased from $16.4 \pm 13.6 \mathrm{~mm}$ (range, $0-50.0 \mathrm{~mm}$ ) preoperatively to $7.4 \pm 6.3$ $\mathrm{mm}$ (range, $-13.97-26.48 \mathrm{~mm})$ postoperatively $(\mathrm{p}<0.001)$.

Compared with the normal contralateral hip, 79 cups (81\%) of 101 hips migrated superiorly (0.2-33.6mm, average $7.7 \mathrm{~mm}$ ) and 22 (19\%) migrated inferiorly $(0.2-16.1 \mathrm{~mm}$, average $4.3 \mathrm{~mm}) .68$ cups (67\%) of $101 \mathrm{hips}$ migrated medially $(0.2-29.0 \mathrm{~mm}$, average $5.2 \mathrm{~mm})$ and $33(33 \%)$ migrated laterally $(0.2-25.7 \mathrm{~mm}$, average $5.4 \mathrm{~mm}$ ). Compared with the contralateral hip, the reconstructed COR was within $5 \mathrm{~mm}$ of vertical and horizontal symmetry (anatomical restoration of hip center) in 24 hips (24\%) and was more than $20 \mathrm{~mm}$ beyond vertical symmetry, horizontal symmetry, or both (nonanatomical restoration of hip center) in 8 hips ( $8 \%)$. The distance of superior migration of reconstructed COR was associated with preoperative LLD $(r=0.311 ; P=0.004)$, postoperative LLD $(r=0.396 ; p<0.001)$ and positive Trendelenburg sign at the latest follow-up $(r=0.504 ; p<$ 0.001). However, the distance of superior migration of reconstructed COR was not found to be associated with HHS ( $r=0.007 ; \mathrm{P}=0.948)$ or WOMAC ( $r=-0.047 ; \mathrm{P}=0.676)$ at the latest follow-up examination.

101 hips with unilateral THA were classified into a superior migration subgroup (46 hips), inferior migration subgroup (6 hips) and normal subgroup (49 hips). The results of intergroup comparisons among these three subgroups were listed in Table 3. Similarly, these hips were classified into a medial migration subgroup (31 hips), lateral migration subgroup (55 hips) and subgroup with anatomical restoration of COR (15 hips). The results of intergroup comparisons were listed in Table 4. In 79 hips with superior migration of reconstructed COR, the results of intergroup comparisons among anatomical restoration subgroup (33 hips), mild migration subgroup (22 hips), moderate migration subgroup (17 hips) and severe migration subgroup (7 hips) were listed in Table 5.

\section{Table 3 Comparisons of perioperative parameters among the subgroup with anatomical restoration, superior migration, and inferior migration}

$\mathrm{COR}=$ center of rotation, $\mathrm{THA}=$ total hip arthroplasty, $\mathrm{BMI}=$ bone mass index, $\mathrm{ORIF}=$ open reduction and internal fixation, $L L D=$ leg length discrepancy, HHS= Harris hip score, WOMAC= Western Ontario and McMaster Universities Arthritis Index, $\mathrm{HO}=$ heterotopic ossification

* Indicate the hips with grade 2 or 3 Paprosky acetabular bone defect 


\begin{tabular}{|c|c|c|c|c|}
\hline parameters & $\begin{array}{l}\text { superior migration } \\
(n=46)\end{array}$ & $\begin{array}{l}\text { anatomical } \\
\text { restoration }(n=49)\end{array}$ & $\begin{array}{l}\text { inferior } \\
\text { migration }(n=6)\end{array}$ & $\begin{array}{l}\mathrm{P} \\
\text { value }\end{array}$ \\
\hline Age at THA (year) ${ }^{\#}$ & $\begin{array}{l}50.5(43.00 \text { to } \\
58.00)\end{array}$ & $50.0(44.50$ to 57.00$)$ & $\begin{array}{l}39.0(32.50 \text { to } \\
58.00)\end{array}$ & 0.464 \\
\hline Treatment interval (month)\# & $\begin{array}{l}42.0(21.00 \text { to } \\
146.25)\end{array}$ & $60.0(17.50$ to 178.00$)$ & $\begin{array}{l}35.5(18.00 \text { to } \\
240.00)\end{array}$ & 0.987 \\
\hline $\mathrm{BMI} \S$ & $25.9(3.4)$ & $25.7(4.0)$ & $26.0(3.1)$ & 0.973 \\
\hline Female & $9(19.6 \%)$ & $14(28.6 \%)$ & $2(33.3 \%)$ & 0.526 \\
\hline Preop. HHS ${ }^{\#}$ & $\begin{array}{l}52.5(41.75 \text { to } \\
63.25)\end{array}$ & $52.0(43.00$ to 66.00$)$ & $\begin{array}{l}43.0(33.00 \text { to } \\
53.25)\end{array}$ & 0.321 \\
\hline Preop. WOMAC\# & $\begin{array}{l}52.5(34.75 \text { to } \\
62.25)\end{array}$ & $50.0(37.00$ to 65.50$)$ & $\begin{array}{l}56.0(35.00 \text { to } \\
74.75)\end{array}$ & 0.797 \\
\hline $\begin{array}{l}\text { Preop. positive Trendelenburg } \\
\text { sign }\end{array}$ & $23(50.0 \%)$ & $30(61.2 \%)$ & $2(33.3 \%)$ & 0.306 \\
\hline Preop. LLD $(\mathrm{mm})^{\#}$ & $\begin{array}{l}15.7(10.00 \text { to } \\
27.00)\end{array}$ & $10.0(0$ to 20.00$)$ & $\begin{array}{l}37.5(11.25 \text { to } \\
46.25)\end{array}$ & 0.024 \\
\hline Complex fracture pattern & $18(39.1 \%)$ & $15(30.6 \%)$ & $5(83.3 \%)$ & 0.036 \\
\hline Initial ORIF treatment" & $28(60.9 \%)$ & $32(65.3 \%)$ & $5(83.3 \%)$ & 0.601 \\
\hline Severe bone defect* ${ }^{\natural}$ & $23(50.0 \%)$ & $16(32.7 \%)$ & $4(66.7 \%)$ & 0.121 \\
\hline Diameter of cup $(\mathrm{mm})^{\#}$ & $\begin{array}{l}54.0(50.00 \text { to } \\
56.00)\end{array}$ & $54.0(50.00$ to 56.00$)$ & $\begin{array}{l}54.0(50.50 \text { to } \\
57.00)\end{array}$ & 0.923 \\
\hline Use of an elevated liner & $32(69.6 \%)$ & $27(55.1 \%)$ & $4(66.7 \%)$ & 0.379 \\
\hline $\begin{array}{l}\text { Acetabular inclination angle } \\
\left({ }^{\circ}\right)^{\S}\end{array}$ & $38.7(6.9)$ & $37.7(6.9)$ & 33.6(15.4) & 0.307 \\
\hline $\begin{array}{l}\text { Acetabular anteversion angle } \\
\left({ }^{\circ}\right)^{\S}\end{array}$ & $17.7(7.6)$ & 18.6(6.8) & $14.9(7.7)$ & 0.456 \\
\hline Bulk autograft ${ }^{9}$ & $4(8.7 \%)$ & $4(8.2 \%)$ & $1(16.7 \%)$ & 0.610 \\
\hline $\begin{array}{l}\text { Distance of horizontal } \\
\text { migration }(\mathrm{mm})\end{array}$ & $3.0(-2.31$ to 6.64$)$ & $1.4(-1.23$ to 5.36$)$ & $\begin{array}{l}1.6(-5.98 \text { to } \\
12.61)\end{array}$ & 0.726 \\
\hline Postop. Trendelenburg sign & $13(28.3 \%)$ & $4(8.2 \%)$ & $1(16.7 \%)$ & 0.032 \\
\hline Postop. HHS" & $\begin{array}{l}95.0(89.75 \text { to } \\
97.75)\end{array}$ & $93.0(90.00$ to 98.50$)$ & $\begin{array}{l}95.0(68.25 \text { to } \\
97.75)\end{array}$ & 0.956 \\
\hline Postop. WOMAC \# & $4.0(0.75$ to 8.00$)$ & $6.0(1.00$ to 9.00$)$ & $\begin{array}{l}4.5(1.50 \text { to } \\
31.50)\end{array}$ & 0.623 \\
\hline Postop. $\mathrm{HO}^{9}$ & $7(15.2 \%)$ & $10(20.4 \%)$ & $0(0 \%)$ & 0.571 \\
\hline
\end{tabular}


$\S$ The normally distributed data are expressed as mean and standard deviation

\# The non-normally distributed data are expressed as median and IQR.

- The qualitative data are expressed as numbers and percentages.

$\natural$ The negative values represented lateral migration

Table 4 Comparisons of perioperative parameters among the subgroup with anatomical restoration, medial migration, and lateral migration

$\mathrm{COR}=$ center of rotation, $\mathrm{THA}=$ total hip arthroplasty, $\mathrm{BMI}=$ bone mass index, ORIF=open reduction and internal fixation, $L L D=$ leg length discrepancy, HHS=Harris hip score, WOMAC= Western Ontario and McMaster Universities Arthritis Index, $\mathrm{HO}=$ heterotopic ossification

* Indicate the hips with grade 2 or 3 Paprosky acetabular bone defect

$\S$ The normally distributed data are expressed as mean and standard deviation

\# The non-normally distributed data are expressed as median and IQR.

The qualitative data are expressed as numbers and percentages.

$\sharp$ The negative values represented superior migration

Table 5 Comparison of perioperative parameters among the subgroup with anatomical restoration, mild, moderate and severe migration 
parameters medial

migration

(n=31)

Age at THA (year) ${ }^{\#}$

$50.0(34.00$ to

$56.00)$

Treatment interval (month) ${ }^{\#} \quad 24.0(12.00$ to 72.00)

BMI§

Female

Preop. HHS

Preop. WOMAC\#

Preop. positive

Trendelenburg sign

Preop. LLD (mm) \#

Complex fracture pattern

Initial ORIF treatment

Severe bone defect*

Diameter of cup(mm) \#

Use of an elevated liner

Acetabular inclination angle

$\left({ }^{\circ}\right)^{\S}$

Acetabular anteversion angle

$\left({ }^{\circ}\right)^{\S}$

Bulk autograft

Distance of vertical

migration $(\mathrm{mm})$ \#

Postop. Trendelenburg sign ${ }^{9}$

Postop. HHS\#

Postop. WOMAC\#

Postop. $\mathrm{HO}^{9}$

25.7(3.6)

$3(9.7 \%)$

$63.0(41.00$ to

73.00)

$50.0(29.00$ to 70.00)

16(51.0\%)

$15.0(9.30$ to

25.10)

13(41.9\%)

$21(67.7 \%)$

$14(45.2 \%)$

$54.0(54.00$ to $50.00)$

$19(61.3 \%)$

39.6(7.2)

$17.5(6.6)$

$5(16.1 \%)$

$-6.8(-10.44$ to $-2.42)$

$5(16.1 \%)$

$93.0(90.00$ to 100.00)

$5.0(0$ to 8.00$)$

$8(25.8 \%)$ anatomical restoration

$(n=55)$

lateral migration

$(n=15)$

$\mathrm{P}$
value

0.376

$57.00)$

$47.0(23.00$ to 204.00$)$

$120.0(36.00$ to

0.015

156.00)

25.9(3.5)

25.7(4.6)

0.954

18(32.7\%)

$4(26.7 \%)$

0.053

$50.0(42.00$ to 63.00$)$

$57.0(45.00$ to 63.00)

$53.0(40.00$ to 67.00$)$

$52.0(36.00$ to $58.00)$

8(53.3\%)

0.961

$31(56.4 \%)$

$15.3(25.00$ to 0$)$

$16.0(7.80$ to 30.00)

0.688

$9(60.0 \%)$

0.075

$16(29.1 \%)$

8(53.3\%)

0.655

$36(65.5 \%)$

$18(32.7 \%)$

11(73.3\%)

0.017

$54.0(56.00$ to 50.00$)$

$56.0(52.00$ to 60.00)

$33(60.0 \%)$

11(73.3\%)

0.690

$37.6(6.7)$

35.5(10.7)

0.208

$19.0(7.5)$

15.3(7.0)

0.182

$3(5.5 \%)$

$1(6.7 \%)$

0.229

$-3.5(-8.31$ to -0.18$)$

$-3.1(-14.46$ to

0.75 )

0.513

$7(12.7 \%)$

$6(40.0 \%)$

0.062

$93.0(89.00$ to 97.00$)$

$94.0(93.00$ to 97.00)

$5.0(2.00$ to 10.00$)$

$4.0(3.00$ to 6.00$)$

0.813

$7(12.7 \%)$

2(13.3\%)

0.277 


\begin{tabular}{|c|c|c|c|c|c|}
\hline parameters & $\begin{array}{l}\text { anatomical } \\
\text { restoration }(n=33)\end{array}$ & & $\begin{array}{l}\text { moderate } \\
\text { migration( } n=17)\end{array}$ & $\begin{array}{l}\text { severe } \\
\text { migration( } n=7)\end{array}$ & \\
\hline $\begin{array}{l}\text { Age at THA } \\
\text { (year) }\end{array}$ & $\begin{array}{l}52.0(45.00 \text { to } \\
57.00)\end{array}$ & $\begin{array}{l}52.0(43.75 \\
\text { to } 60.25)\end{array}$ & $\begin{array}{l}48.0(37.00 \text { to } \\
59.00)\end{array}$ & $51.0(50.00$ to 55.00$)$ & 0.557 \\
\hline $\begin{array}{l}\text { Treatment } \\
\text { interval (month)\# }\end{array}$ & $\begin{array}{l}60.0(16.50 \text { to } \\
198.00)\end{array}$ & $\begin{array}{l}36.0(16.75 \\
\text { to } 125.75)\end{array}$ & $\begin{array}{l}48.0(15.00 \text { to } \\
216.00)\end{array}$ & $96.0(24.00$ to 192.00$)$ & 0.808 \\
\hline $\mathrm{BMI}$ & $25.6(4.2)$ & $26.3(3.3)$ & $24.3(2.8)$ & 28.4(3.7) & 0.092 \\
\hline Female & $6(18.2 \%)$ & $4(18.2 \%)$ & $4(23.5 \%)$ & $1(14.3 \%)$ & 0.947 \\
\hline Preop. HHS\# & $\begin{array}{l}63(43.50 \text { to } \\
71.50)\end{array}$ & $\begin{array}{l}56.5(40.75 \\
\text { to } 65.25)\end{array}$ & $\begin{array}{l}49.0(44.00 \text { to } \\
64.00)\end{array}$ & $49.0(21.00$ to 63.00$)$ & 0.548 \\
\hline Preop. WOMAC\# & $\begin{array}{l}51.0(29.00 \text { to } \\
62.50)\end{array}$ & $\begin{array}{l}51.0(32.00 \\
\text { to } 56.00)\end{array}$ & $\begin{array}{l}55.0(41.00 \text { to } \\
70.50)\end{array}$ & $56.0(27.00$ to 61.00$)$ & 0.426 \\
\hline $\begin{array}{l}\text { Preop. positive } \\
\text { Trendelenburg } \\
\text { sign }\end{array}$ & $19(57.6 \%)$ & $8(36.4 \%)$ & $10(58.8 \%)$ & $5(71.4 \%)$ & 0.285 \\
\hline $\begin{array}{l}\text { Preop. LLD } \\
(\mathrm{mm})^{\#}\end{array}$ & $\begin{array}{l}10.0(0.40 \text { to } \\
20.00)\end{array}$ & $\begin{array}{l}12.5(8.75 \\
\text { to } 20.53)\end{array}$ & $\begin{array}{l}16.1(10.00 \text { to } \\
23.00)\end{array}$ & $35.0(24.00$ to 40.00$)$ & 0.022 \\
\hline $\begin{array}{l}\text { Complex } \\
\text { fracture pattern }\end{array}$ & $9(27.3 \%)$ & $6(27.3 \%)$ & $6(35.3 \%)$ & $6(85.7 \%)$ & 0.032 \\
\hline $\begin{array}{l}\text { Initial ORIF } \\
\text { treatment }\end{array}$ & $21(63.6 \%)$ & $14(63.6 \%)$ & $9(52.9 \%)$ & $5(71.4 \%)$ & 0.849 \\
\hline $\begin{array}{l}\text { Severe bone } \\
\text { defect* }\end{array}$ & $11(33.3 \%)$ & $10(45.5 \%)$ & $8(47.1 \%)$ & $5(71.4 \%)$ & 0.294 \\
\hline $\begin{array}{l}\text { Diameter of } \\
\operatorname{cup}(\mathrm{mm})^{\#}\end{array}$ & $\begin{array}{l}54.0(50.00 \text { to } \\
55.00)\end{array}$ & $\begin{array}{l}54.0(51.50 \\
\text { to } 56.00)\end{array}$ & $\begin{array}{l}50.0(50.00 \text { to } \\
55.00)\end{array}$ & $56.0(54.00$ to 64.00$)$ & 0.081 \\
\hline $\begin{array}{l}\text { Use of an } \\
\text { elevated liner }\end{array}$ & $17(51.5 \%)$ & $15(68.2 \%)$ & $12(70.6 \%)$ & $5(71.4 \%)$ & 0.459 \\
\hline $\begin{array}{l}\text { Acetabular } \\
\text { inclination angle } \\
\left({ }^{\circ}\right)^{\S}\end{array}$ & $37.7(7.8)$ & $37.3(6.8)$ & $38.9(7.8)$ & $42.2(4.3)$ & 0.438 \\
\hline $\begin{array}{l}\text { Acetabular } \\
\text { anteversion } \\
\text { angle }\left({ }^{\circ}\right)^{\S}\end{array}$ & $17.8(6.4)$ & 16.8(8.1) & 19.3(7.9) & $16.7(5.1)$ & 0.728 \\
\hline Bulk autograft 9 & $3(9.1 \%)$ & $0(0 \%)$ & $3(17.6 \%)$ & $1(14.3 \%)$ & 0.139 \\
\hline $\begin{array}{l}\text { Postop. LLD } \\
(\mathrm{mm})^{\#}\end{array}$ & $4.9(2.26$ to 9.13$)$ & $\begin{array}{l}4.0(2.90 \text { to } \\
9.70)\end{array}$ & $\begin{array}{l}6.2(1.73 \text { to } \\
11.42)\end{array}$ & $17.5(9.21$ to 20.25$)$ & 0.010 \\
\hline Postop. & $2(6.1 \%)$ & $1(4.5 \%)$ & $7(41.2 \%)$ & $5(71.4 \%)$ & 0.001 \\
\hline
\end{tabular}




\begin{tabular}{|c|c|c|c|c|c|}
\hline Postop. HHS & $\begin{array}{l}93.0(90.00 \text { to } \\
98.50)\end{array}$ & $\begin{array}{l}97.0(89.00 \\
\text { to } 100.00)\end{array}$ & $\begin{array}{l}93.0(90.50 \text { to } \\
97.00)\end{array}$ & $94.0(83.00$ to 97.00$)$ & 0.587 \\
\hline $\begin{array}{l}\text { Postop. } \\
\text { WOMAC\# }\end{array}$ & $6.0(1.00$ to 9.00$)$ & $\begin{array}{l}3.0(0 \text { to } \\
6.25)\end{array}$ & $\begin{array}{l}5.0(2.00 \text { to } \\
8.00)\end{array}$ & $4.0(3.00$ to 13.00$)$ & 0.424 \\
\hline Postop. HO & $6(18.2 \%)$ & $3(13.6 \%)$ & $3(17.6 \%)$ & $1(14.3 \%)$ & 0.969 \\
\hline $\begin{array}{l}\text { Postop. sciatic } \\
\text { injury }\end{array}$ & $5(15.2 \%)$ & $0(0 \%)$ & $1(5.9 \%)$ & $0(0 \%)$ & 0.193 \\
\hline $\begin{array}{l}\text { Distance of } \\
\text { vertical } \\
\text { migration }(\mathrm{mm})^{\#}\end{array}$ & $\begin{array}{l}-2.4(-3.41 \text { to } \\
-1.55)\end{array}$ & $\begin{array}{l}-7.5(-8.34 \\
\text { to }-6.77)\end{array}$ & $\begin{array}{l}-11.0(-13.80 \text { to } \\
-10.64)\end{array}$ & $-21.1(-28.41$ to -20.24$)$ & 0.001 \\
\hline $\begin{array}{l}\text { Distance of } \\
\text { horizontal } \\
\text { migration }(\mathrm{mm})^{\#}\end{array}$ & $2.1(-0.01$ to 6.02$)$ & $\begin{array}{l}3.6(-1.50 \\
\text { to } 6.07)\end{array}$ & $\begin{array}{l}3.3(-0.24 \text { to } \\
8.37)\end{array}$ & $-2.3(-11.00$ to 2.68$)$ & 0.232 \\
\hline
\end{tabular}

$\mathrm{COR}=$ center of rotation, $\mathrm{THA}=$ total hip arthroplasty, $\mathrm{BMI}=$ bone mass index, ORIF= open reduction and internal fixation, LLD= leg length discrepancy, HHS= Harris hip score, WOMAC= Western Ontario and McMaster Universities Arthritis Index, $\mathrm{HO}=$ heterotopic ossification

* Indicate the hips with grade 2 or 3 Paprosky acetabular bone defect

$\S$ The normally distributed data are expressed as mean and standard deviation

\# The non-normally distributed data are expressed as median and IQR.

The qualitative data are expressed as numbers and percentages.

$\sharp$ The negative values represented superior and lateral migration

\section{Complications}

Perioperative complications included iatrogenic sciatic nerve injury in 8 hips and periprosthetic infection in 4 hips. Six hips with initial ORIF treatment and three hips with non-ORIF treatment already had a sciatic nerve lesion before the THA and only one of them presented with a worsening of the previous nerve lesion. The additional 7 hips had a new-onset sciatic nerve injury after THA. Three patients had a full resolution within three months after THA, three patients had a full resolution of sensory disturbance, but partial resolution of foot drop one year after THA. Two patients did not reveal any improvement in sensory disturbance and foot drop.

In the 4 patients who developed periprosthetic infection, microbial culture tests were used to confirm this diagnosis. All patients had a history of ORIF. The four hips were treated with implant removal, debridement, and antibiotic-loaded articulating cement spacers. Three of them acquired an infection control and received a 
successful two-stage revision arthroplasty. The infection remained uncontrolled in another patient and he refused to receive any further surgery.

After surgery, 17 hips demonstrated HO with no adverse clinical effects. Five hips had Brooker class I HO, 7 hips had class II and 5 hips had class III. No patient required a further procedure for $\mathrm{HO}$.

\section{Discussion}

Although THA after failed treatment of an acetabular fracture is a technically demanding procedure, reconstruction with cementless components can achieve satisfactory prosthesis survivorship and clinical results $[8,9,10,11,12,13]$. Our clinical findings in this young, active patient population affected by high-energy trauma were encouraging with a mean HHS of 93 and WOMAC of 5.8 at the latest follow-up examination. Perioperative complications included iatrogenic sciatic nerve injury in 8 hips (7.5\%), periprosthetic infection in 4 hips (3.7\%), and HO in 17 hips (15.9\%).

A series of published studies have discussed the significances of the precise location of the COR in THA performed for patients with developmental dysplasia of the hip (DDH) [21], rheumatoid arthritis (RA) [22] and in revision situations [23]. However, in the published studies focusing on cementless acetabular reconstruction for failed treatment of acetabular fractures, only a few discussed the association of reconstruction accuracy in terms of hip COR with clinical results. Ranawat et al [10] reported only in three hips (9\%) that the position of the COR was greater than $20 \mathrm{~mm}$ beyond vertical symmetry, horizontal symmetry, or both when compared with the unaffected hip. They found that nonanatomic restoration of COR was ultimately associated with need for revision surgery and with intraoperative discovery of a segmental acetabular defect. However, this did not correlate with prior treatment and HHS or with polyethylene wear.

In the current series, we found that a wide range of distribution of the reconstructed COR. The reconstructed COR was within $5 \mathrm{~mm}$ of vertical and horizontal symmetry (anatomical restoration of COR) in 24 hips (24\%) and was more than $20 \mathrm{~mm}$ beyond vertical symmetry, horizontal symmetry, or both (nonanatomical restoration of $\mathrm{COR}$ ) in 8 hips (8\%). This distribution model reflected the abnormal anatomy of the acetabulum after initial fractures and treatments, and was further affected by the hardware and bone defect during implantation of the cementless cups. Consequently, compared with THA reconstruction for DDH or RA, the implant reconstruction for acetabular fractures become more irregular and technically demanding, which is analogous with situations in revision THA.

The results of horizontal intergroup comparisons suggested that only some preoperative parameters, including treatment interval, grade of acetabular bone defect and diameter of cup, had significant differences. For vertical intergroup comparisons, only percentage of postoperative positive Trendelenburg sign was significantly higher in superior migration subgroup than that in subgroup with anatomical restoration of COR ( $28.3 \%$ vs $8.2 \%, \mathrm{P}=0.015)$. Moreover, the distance of superior migration of reconstructed COR was associated with positive Trendelenburg sign at the latest follow-up $(r=0.504 ; p<0.001)$. We made further investigations for 79 hips with superior migration of reconstructed COR. The percentage of postoperative positive Trendelenburg sign were equally higher in severe migration subgroup than that in anatomical restoration subgroup and in mild migration subgroup. These results suggested that a superiorly migrated COR appeared to exert a negative effect on abductor muscle function by decreasing the abductor moment arm, but did not detect any significant 
correlations with worse clinical outcomes and higher complication rate. Consequently, the abductor muscle function should be emphasized in postoperative rehabilitation program for this special patient population.

The main strengths of our study included a relatively large sample size and a high follow-up rate. However, we acknowledge that our study was not without its limitations. First, as this was a retrospective study, there are associated inherent limitations, most importantly the absence of control cases with which to compare outcomes. Patient selection, measurement and interviewer bias may affect functional assessment outcomes. Second, although the cases enrolled in the study were exclusively from one single center, all THAs were performed by several senior surgeons, which may affect the validity of our findings. Third, the multiple cementless acetabular component designs and different interface selections were included in our series.

\section{Conclusions}

In conclusion, our study revealed that despite the technically demanding nature and a relatively high complication rate, cementless THA performed in patients with failed treatments for acetabular fractures achieved predictable clinical and radiographic outcomes. A superiorly migrated COR appeared to exert negative effect on abductor muscle function and surgeons should pay proper attention to the accuracy of hip COR reconstruction.

\section{Abbreviations}

COR: center of rotation

THAs: total hip arthroplasties

HHS: Harris hip score

WOMAC: Western Ontario and McMaster Universities Arthritis Index

ORIF: open reduction and internal fixation

TM: trabecular metal

AP: anteroposterior

HO: heterotopic ossification

LLD: leg length discrepancy

PACS: picture archiving and communication system

SD: standard deviation

DDH: developmental dysplasia of the hip

\section{Declarations}


Ethics approval: Implementation of this study was approved by the Institutional Review Board of Beijing Jishuitan Hospital, and all methods were performed in accordance with the Declaration of Helsinki.

Consent to participate: Informed consent from all participating patients were obtained.

Consent to publication: Not applicable

Availability of data and material: Not applicable

Competing interest: The authors declare that they have no competing interests.

Funding: No funds, grants, or other support was received.

Authors' contributions: All authors contributed to the study conception and design. Material preparation, data collection, and analysis were performed by Mingxue Chen, Zhuyi Ma, Tao Bian, Shaoliang Li and Weiyi Li. The manuscript was written by Liang Zhang. Yixin Zhou edited the manuscript and approved the final version.

Acknowledgements: Not applicable

\section{References}

1. Bicanic G, Delimar D, Delimar M, Pecina M. Influence of the acetabular cup position on hip load during arthroplasty in hip dysplasia. Int Orthop. 2009;33:397-402.

2. Sariali E, Klouche S, Mamoudy P. Investigation into three-dimensional hip anatomy in anterior dislocation after THA. Influence of the position of the hip rotation center. Clin Biomech. 2012;27:562-567.

3. Lum ZC, Dorr LD. Restoration of center of rotation and balance of THR. J Orthop. 2018;15:992-996.

4. Bonnin MP, Archbold PH, Basiglini L, Fessy MH, Beverland DE. Do we medialise the hip center of rotation in total hip arthroplasty? Influence of acetabular offset and surgical technique. Hip Int. 2012;22:371-378.

5. Kayani B, Konan S, Thakrar RR, Huq SS, Haddad FS. Assuring the long-term total joint arthroplasty: a triad of variables. Bone Joint J. 2019;101-B(1_Supple_A): 11-18.

6. Daurka JS, Pastides PS, Lewis A, Rickman M, Bircher MD. Acetabular fractures in patients aged $>55$ years: a systematic review of the literature. Bone Joint J. 2014;96-B (2):157-163.

7. Sierra RJ, Mabry TM, Sems SA, Berry DJ. Acetabular fractures: the role of total hip replacement. Bone Joint J. 2013;95-B (11 Suppl A):11-16.

8. Huo MH, Solberg BD, Zatorski LE, Keggi KJ. Total hip replacements done without cement after acetabular fractures: a 4- to 8-year follow-up study. J Arthroplasty. 1999;14:827-831.

9. Bellabarba C, Berger RA, Bentley CD, Quigley LR, Jacobs JJ, Rosenberg AG, et al. Cementless acetabular reconstruction after acetabular fracture. J Bone Joint Surg Am. 2001;83:868-876.

10. Ranawat A, Zelken J, BA, Helfet D, Buly R. Total hip arthroplasty for posttraumatic arthritis after acetabular fracture. J Arthroplasty. 2009;24:759-767.

11. Zhang L, Li Y, Xu H, Guo X, Zhou Y. Total hip arthroplasty for failed treatment of acetabular fractures: a 5year follow-up study. J Arthroplasty. 2011;26:1189-1193. 
12. Makridis KG, Obakponovwe $O$, Bobak $P$, Giannoudis PV. Total hip arthroplasty after acetabular fracture: incidence of complications, reoperation rates and functional outcomes: evidence today. J Arthroplasty. 2014;29:1983-1990.

13. Salama W, Ditto P, Mousa S, Khalefa A, Sleem A, Ravera L, et al. Cementless total hip arthroplasty in the treatment after acetabular fractures. Eur J Orthop Surg Traumatol. 2018;28:59-64.

14. Paprosky WG, Perona PG, Lawrence JM. Acetabular defect classification and surgical reconstruction in revision arthroplasty: a 6-year follow-up evaluation. J Arthroplasty. 1994;9:33-44.

15. DeLee JG, Charnley J. Radiological demarcation of cemented sockets in total hip. Clin Orthop Relat Res. 1976;121:20-32.

16. Moore MS, McAuley JP, Young AM, Engh CA Sr. Radiographic signs of osseointegration in porous-coated acetabular components. Clin Orthop Relat Res. 2006;444:176-183.

17. Brooker AF, Bowerman JW, Robinson RA, Riley LH Jr. Ectopic ossification following total hip replacement: Incidence and a method of classification. J Bone Joint Surg Am. 1973;55:1629-1632.

18. Widmer KH. A simplified method to determine acetabular cup anteversion from plain radiographs. $\mathrm{J}$ Arthroplasty. 2004;19:387-390.

19. Lewinnek GE, Lewis JL, Tarr R, Compere CL, Zimmerman JR. Dislocations after total hip replacement arthroplasties. J Bone Joint Surg Am. 1978;60:217-220.

20. Martell JM, Pierson RH 3rd, Jacobs JJ, Rosenberg AG, Maley M, Galante JO. Primary total hip reconstruction with a titanium fiber-coated prosthesis inserted without cement. J Bone Joint Surg Am. 1993;75:554-571.

21. Fukushi Jl, Kawano I, Motomura G, Hamai S, Kawaguchi KI, Nakashima Y. Does hip center location affect the recovery of abductor moment after total hip arthroplasty? Orthop Traumatol Surg Res. 2018;104:1149-1153.

22. Zhen P, Li X, Zhou S, Lu H, Chen H, Liu J. Total hip arthroplasty to treat acetabular protrusions secondary to rheumatoid arthritis. J Orthop Surg Res. 2018;13:92.

23. Kim DH, Cho SH, Jeong ST, Park HB, Hwang SC, Park JS. Restoration of the center of rotation in revision total hip arthroplasty. J Arthroplasty. 2010;25:1041-1046. 